\title{
Discrimination between bycatch and other causes of cetacean and pinniped stranding
}

\author{
Yara Bernaldo de Quirós ${ }^{1,2}$, Meghan Hartwick ${ }^{1,3}$, David S. Rotstein ${ }^{4}$, \\ Michael M. Garner ${ }^{5}$, Andrea Bogomolni ${ }^{1}$, William Greer ${ }^{6,7}$, Misty E. Niemeyer ${ }^{3}$, \\ Greg Early ${ }^{7}$, Frederick Wenzel $^{6}{ }$, Michael Moore ${ }^{1, *}$ \\ ${ }^{1}$ Woods Hole Oceanographic Institution, Biology Department, Woods Hole, Massachusetts 02543, USA \\ ${ }^{2}$ Institute of Animal Health, University of Las Palmas de Gran Canaria, Arucas, Las Palmas, Spain \\ ${ }^{3}$ International Fund for Animal Welfare, Yarmouth Port, Massachusetts 02543, USA \\ ${ }^{4}$ Marine Pathology Services, Olney, Maryland 20832, USA \\ ${ }^{5}$ NW ZooPath, 654 W Main St, Monroe, Washington 98272, USA \\ ${ }^{6}$ NOAA NMFS Northeast Fisheries Science Center, Woods Hole, Massachusetts 02543, USA \\ ${ }^{7}$ Integrated Statistics, Woods Hole, Massachusetts 02543, USA
}

\begin{abstract}
The challenge of identifying cause of death in discarded bycaught marine mammals stems from a combination of the non-specific nature of the lesions of drowning, the complex physiologic adaptations unique to breath-holding marine mammals, lack of case histories, and the diverse nature of fishing gear. While no pathognomonic lesions are recognized, signs of acute external entanglement, bulging or reddened eyes, recently ingested gastric contents, pulmonary changes, and decompression-associated gas bubbles have been identified in the condition of peracute underwater entrapment (PUE) syndrome in previous studies of marine mammals. We reviewed the gross necropsy and histopathology reports of 36 cetaceans and pinnipeds including 20 directly observed bycaught and 16 live stranded animals that were euthanized between 2005 and 2011 for lesions consistent with PUE. We identified 5 criteria which present at significantly higher rates in bycaught marine mammals: external signs of acute entanglement, red or bulging eyes, recently ingested gastric contents, multi-organ congestion, and disseminated gas bubbles detected grossly during the necropsy and histologically. In contrast, froth in the trachea or primary bronchi, and lung changes (i.e. wet, heavy, froth, edema, congestion, and hemorrhage) were poor indicators of PUE. This is the first study that provides insight into the different published parameters for PUE in bycatch. For regions frequently confronted by stranded marine mammals with non-specific lesions, this could potentially aid in the investigation and quantification of marine fisheries interactions.
\end{abstract}

KEY WORDS: Bycatch · Gas bubbles · Stranding · Cetacean · Pinniped · Fishery · Peracute underwater entrapment

\section{INTRODUCTION}

Bycaught marine mammals that die peracutely are those which become entangled in fishing gear such as gillnets and trawls where the proximate cause of death is forced submersion (Kuiken 1994). Peracute underwater entrapment (PUE) is the term applied to mortalities of marine mammals caused by entangle-

${ }^{*}$ Corresponding author: mmoore@whoi.edu ment and forced submersion and can entail complex determinations of ultimate cause of death (Moore et al. 2013). The challenge of identifying PUE stems from the non-specific lesions associated with drowning, and the physiologic adaptations unique to breathholding marine mammals.

In human forensic science, drowning is considered asphyxiation with small or large volumes of water

(C) The authors 2018. Open Access under Creative Commons by Attribution Licence. Use, distribution and reproduction are unrestricted. Authors and original publication must be credited. 
occluding the airways. In 10-15\% of human drownings it is believed that the larynx spasms and water does not reach the lungs (Di Maio \& Di Maio 1993). White or hemorrhagic edema can be found in nostrils, mouth, and airways. Humans hold their breath until a break point of high levels of carbon dioxide and low levels of oxygen are reached, and water is involuntarily inhaled (Di Maio \& Di Maio 1993).

Marine mammals have developed adaptations for breath holding. Harbor seals Phoca vitulina can dive to up to $466 \mathrm{~m}$ deep and for as long as $31 \mathrm{~min}$, although most dives are shallower dives of 1-3 min (Stewart 2017). Gray seals Halichoerus grypus can dive deeper than $300 \mathrm{~m}$ and for about $30 \mathrm{~min}$, but most dives are within shallow waters $(60-100 \mathrm{~m}$ deep) and short (4-10 min; Hall \& Russel 2017). Harbor porpoises Phocoena phocoena can dive up to $220 \mathrm{~m}$ deep and for as long as $7 \mathrm{~min}$, but most dives are less than $20 \mathrm{~m}$ deep and last $\sim 1 \mathrm{~min}$ (Bjorge \& Tolley 2017, Stewart 2017). Strenuous activity, such as the reaction of an animal when it realizes that it is entrapped, creates more metabolic demand than the animal may be adapted for. The metabolic rate of an odontocete may increase $30 \%$ in a flight response (Williams et al. 2017). The mechanisms that marine mammals use to compensate for long periods of breath-holding at depths (alveolar collapse, tracheobronchial compression, and blood redistribution; Piantadosi \& Thalmann 2004, Moore et al. 2011) may inhibit inspiration during forced submersion (Berta et al. 2006), leading to cardiac inhibition and severe laryngospasm, hypoxia, and convulsions (Papadodima et al. 2010). Carbon dioxide narcosis has also been suggested; however, studies in shallow-diving terrestrial species (beaver and otter) have shown that toxic levels of $\mathrm{CO}_{2}$ do not accumulate before the onset of hypoxia (Ludders et al. 2009).

Currently, there is no established pathognomonic lesion for drowning (Lunetta \& Modell 2005, Piette \& De Letter 2006). As in human forensic pathology, the history and necropsy findings in marine mammals are important criteria in reaching a diagnosis of PUE. The signs associated with forced underwater submersion in marine mammals include evidence of acute entanglement such as linear impressions encircling the head, neck, body, and appendages as well as lacerations at the gape of the mouth; post mortem mutilations caused by removal of the animal from gear (Kuiken 1994, Cox et al. 1998, Jepson et al. 2013); stable froth in airways, heavy, reddened lungs and eyes, and generalized congestion (Duignan et al. 2003, Jepson et al. 2013).
Jepson et al. (2005) and Moore et al. (2009) reported the finding of gas bubbles in PUE marine mammals as a consequence of post mortem offgassing from hauling out deceased animals with nitrogen saturated tissues. These gas bubbles were likely similar to those identified by Fernández et al. (2005) demonstrating the development of a decompression sickness-like condition in diving marine mammals caused by inert gases coming out of solution into tissues and venous circulation (Vann et al. 2011). A recent study showed that the quantity of macroscopic gas bubbles in bycaught animals was significantly higher than in stranded marine mammals (Bernaldo de Quirós et al. 2013b). That study also demonstrated that the gas bubbles were mainly composed of nitrogen, reinforcing the decompression hypothesis proposed by Moore et al. (2009). Decompression sickness has been diagnosed in sea turtles with PUE (García-Párraga et al. 2014).

We retrospectively studied the gross necropsy and histopathology reports of known fishery bycaught cases and compared them to those of stranded marine mammals for findings previously reported in association with forced submersion (Kuiken 1994, Cox et al. 1998, Knieriem \& García-Hartmann 2001, Jepson et al. 2013, Moore \& Barco 2013). The goal of this study was not to investigate the complex pathophysiologic processes which contribute to ultimate cause of death in marine mammals during PUE, but rather to study the utility of currently published parameters to aid in the detection at necropsy of discarded marine mammal bycatch.

\section{METHODS}

Marine mammal necropsy and histopathology reports from 2005 to 2011 were compared between directly observed bycaught animals $(n=20$; Table 1$)$ and those that were live stranded and euthanized with pentobarbital ( $\mathrm{n}=16$; Table 2 ).

Stranded marine mammals were euthanized after comprehensive health assessment results deemed rescue or rehabilitation unfeasible, which included stranding injury, environmental exposure, and/or severe predator/scavenger damage $(n=3)$, severe acute pre-stranding injury $(\mathrm{n}=2)$, poor health and decompensation during evaluation ( $\mathrm{n}=10)$, and dependent calf/pup $(\mathrm{n}=1)$. The responses to strandings and necropsies were carried out by the International Fund for Animal Welfare (IFAW) between Westport and Sandwich, Massachusetts (MA), USA, including Cape Cod and the Elizabeth Islands. 
Table 1. List of bycaught animals with biological, fishing gear and environmental data. D: Delphinus; L: Lagenorhynchus; P: Phoca; H: Halichoerus

\begin{tabular}{|c|c|c|c|c|c|c|c|c|c|}
\hline Species & $\begin{array}{c}\text { ID } \\
\text { number }\end{array}$ & Gender & Age & $\begin{array}{c}\text { Body } \\
\text { condition }\end{array}$ & $\begin{array}{l}\text { Gear } \\
\text { type }\end{array}$ & $\begin{array}{l}\text { Depth } \\
(\mathrm{m})\end{array}$ & $\begin{array}{c}\text { Soak/tow } \\
\text { duration (h) }\end{array}$ & $\begin{array}{c}\text { Haul } \\
\text { duration (h) }\end{array}$ & $\begin{array}{c}\text { Water } \\
\text { temp. }\left({ }^{\circ} \mathrm{C}\right)\end{array}$ \\
\hline \multicolumn{10}{|l|}{ Cetacean } \\
\hline \multirow[t]{4}{*}{ D. delphis } & DO5725 & Female & Juvenile & Robust & Gillnet & 66 & 144 & 1.3 & 6.1 \\
\hline & DO6887 & Male & Subadult & Thin & Gillnet & 123 & 96 & 1 & 10.0 \\
\hline & DO7295 & Female & Subadult & Robust & Trawl & 101 & - & 5.5 & 13.3 \\
\hline & DO8620 & Male & Subadult & Robust & Trawl & 201 & - & 5.8 & 11.1 \\
\hline L. acutus & DO6762 & Female & Juvenile & Robust & Trawl & 210 & - & 8 & 5.0 \\
\hline \multirow[t]{9}{*}{ P. phocoena } & DO5654 & Male & Calf & Robust & Gillnet & 139 & 48 & 0.4 & - \\
\hline & DO6150 & Male & Calf & Robust & Gillnet & 51 & 24 & 1 & 10.0 \\
\hline & DO6460 & Male & Juvenile & Robust & Gillnet & 82 & 24 & - & 15.6 \\
\hline & DO7041 & Male & Juvenile & Robust & Gillnet & 71 & 52 & 1.6 & 8.3 \\
\hline & DO8080 & Female & Adult & Robust & Gillnet & 73 & 11.5 & 1.3 & 2.8 \\
\hline & DO8133 & Male & Subadult & Robust & Gillnet & 59 & 24 & 0.5 & 7.2 \\
\hline & DO8323 & Female & Subadult & Robust & Gillnet & 106 & 120 & 0.9 & 6.1 \\
\hline & DO8732 & Female & Adult & Robust & Gillnet & 80 & 240 & 1.5 & 6.7 \\
\hline & DO8760 & Male & Calf & Robust & Gillnet & 86 & 247.8 & 2 & 6.7 \\
\hline \multicolumn{10}{|l|}{ Pinniped } \\
\hline \multirow[t]{3}{*}{ H. grypus } & DO5272 & Male & Pup & Thin & Gillnet & 88 & 144 & 1 & 8.1 \\
\hline & DO5694 & Male & Juvenile & Thin & Gillnet & 40 & 120 & 0.8 & 6.9 \\
\hline & DO5695 & Male & Pup & - & Gillnet & 79 & 96 & - & 10.8 \\
\hline \multirow[t]{2}{*}{ P. groenlandicus } & DO5952 & Female & Juvenile & Thin & Gillnet & 214 & 19.8 & 0.7 & 3.9 \\
\hline & DO8414 & Male & Pup & Robust & Gillnet & 53 & 48 & 0.7 & 3.3 \\
\hline P. vitulina & DO6021 & Female & Pup & Robust & Gillnet & 35 & 72 & 0.4 & 3.1 \\
\hline
\end{tabular}

Bycaught animals were obtained through the NOAA Northeast Fisheries Observer Program (NEFOP). All animals were retrieved dead from active commercial fishing nets. Among the 20 bycaught cases, 17 were recovered from gillnets and 3 from trawls. NOAA Fisheries Observers recorded date, depth of net, haul duration, target species, and surface water temperature (Table 1). Deceased animals were transported by road to Woods Hole Oceanographic Institution at Woods Hole, MA, and stored at $4^{\circ} \mathrm{C}$ until necropsied. Necropsies were performed within 24 to $36 \mathrm{~h}$ after death.

At the time of each necropsy, all animals presented in a fresh state of decomposition (Geraci \& Lounsbury 2005). Necropsies of bycaught marine mammals were carried out by NOAA and Woods Hole Oceanographic Institution personnel following Pugliares et al. (2007). Histology samples were collected from all major organs, fixed in 10\% neutral buffered formalin, processed routinely, and stained with hematoxylin and eosin. Slides were examined by board-certified veterinary pathologists.

Necropsy and histopathology reports of bycaught and stranded marine mammals were reviewed for key words or phrases consistent with PUE, including external evidence of acute entanglement or disentanglement (e.g. net marks or line marks); reddened or erythematous conjunctiva and bulging eyes; recently ingested gastric contents; froth in trachea and primary bronchi and/or pulmonary changes (wet, heavy, froth, edema, congestion, and hemorrhage); congestion; and presence of gas bubbles. The presence of congestion and bubbles was studied overall (i.e. presence or absence in the body), including multi-organ distribution (present in 2 or more locations), as well as distribution by location of organs. For congestion, liver, kidney, adrenal, spleen, and heart locations were studied. For gas bubbles, liver, spleen, heart, and lymph nodes were studied. Additionally, the presence of congestion and gas bubbles described in the histopathology reports was analyzed separately from the presence of congestion described in the gross necropsy reports.

The prevalence of these findings was calculated from the total number of cases in the bycaught and stranded group. To determine whether the proportion of animals with these findings differed between bycaught and stranded animals, a chi-squared test was used ( $p<0.05)$. Given the small sample size, the statistical test might be underpowered. Fisher's exact test was also run to compare results with the chi-squared test. We only report p-values from Fisher's exact test when discrepancies between the 2 tests were found. To determine if the manifestation of PUE-associated 
Table 2. List of stranded marine mammals included in the study with biological data and main pathological findings if any. P: Phoca; D: Delphinus; H: Halichoerus; L: Lagenorhynchus

\begin{tabular}{|c|c|c|c|c|c|}
\hline Species & $\begin{array}{l}\text { ID } \\
\text { number }\end{array}$ & Gender & Age & $\begin{array}{l}\text { Body } \\
\text { condition }\end{array}$ & Main pathological findings \\
\hline \multicolumn{6}{|l|}{ Cetacean } \\
\hline \multirow[t]{9}{*}{ D. delphis } & IFAW05-316Dd & Male & Subadult & Robust & No significant findings \\
\hline & IFAW06-013Dd & Male & Subadult & Robust & Pulmonary edema, pneumonia, enteritis \\
\hline & IFAW06-145Dd & Male & Juvenile & Thin & $\begin{array}{l}\text { Crassicauda (blubber), Phyllobothrium (dorsal fin), } \\
\text { hepatic trematodiasis }\end{array}$ \\
\hline & IFAW06-269Dd & Female & Adult & Robust & Renal, neurologic, and cardiovascular disease \\
\hline & IFAW07-036Dd & Male & Adult & Thin & $\begin{array}{l}\text { Moderate to severe atherosclerosis, degenerative } \\
\text { cardiomyopathy, focal pulmonary hemangioma, } \\
\text { moderate rhabdomyolysis }\end{array}$ \\
\hline & IFAW07-109Dd & Male & Juvenile & Emaciated & $\begin{array}{l}\text { Dermatitis, mild rhabdomyolysis, myocardial } \\
\text { necrosis }\end{array}$ \\
\hline & IFAW09-191Dd & Male & Adult & Thin & $\begin{array}{l}\text { Age-related changes (lipofuscinosis, prostatitis, } \\
\text { splenic and lymph node hemosiderosis), and } \\
\text { possible entanglement wounds }\end{array}$ \\
\hline & IFAW10-018Dd & Male & Adult & Robust & No significant findings \\
\hline & IFAW10-069Dd & Female & Juvenile & Thin & Septicemia \\
\hline \multirow[t]{2}{*}{ L. acutus } & IFAW08-032La & Male & Calf & Thin & $\begin{array}{l}\text { Interstitial pneumonia, thrombosis, and edema } \\
\text { around blood vessels in the brain and spinal cord }\end{array}$ \\
\hline & IFAW11-132La & Female & Juvenile & Thin & $\begin{array}{l}\text { Severe hepatic endoparasitism, sarcocysts, } \\
\text { inflammation and fibrosis in the heart }\end{array}$ \\
\hline \multicolumn{6}{|l|}{ Pinniped } \\
\hline H. grypus & IFAW06-202Hg & Male & Pup & Emaciated & $\begin{array}{l}\text { Mandibular fracture and penetrating wound, } \\
\text { exacerbated by parasitism }\end{array}$ \\
\hline P. groenlandicus & IFAW06-133Pg & Male & Adult & Thin & Ulcerative dermatitis \\
\hline \multirow[t]{3}{*}{ P. vitulina } & IFAW05-233Pv & Male & Neonate & Emaciated & $\begin{array}{l}\text { Verminous pneumonia and debilitation from skin } \\
\text { abscess, pyelitis }\end{array}$ \\
\hline & IFAW07-141Pv & Female & Adult & Robust & Bronchointerstitial pneumonia, septicemia \\
\hline & IFAW09-183Pv & Male & Pup & Thin & $\begin{array}{l}\text { Acute hemorrhage and penetrating trauma to skull } \\
\text { and brain from presumptive bite wound; diffuse } \\
\text { interstitial emphysema }\end{array}$ \\
\hline
\end{tabular}

lesions was potentially due to the taxon of the animal rather than if the animal was bycaught or stranded and euthanized, multivariate methods were used icluding a multi-response permutation procedure (MRPP) and principal coordinate analysis (PCoA) using binomial distance. R 3.3.2 statistical software ( $R$ Core Team 2017) and the 'vegan' add-on package (Oksanen et al. 2017) were used.

\section{RESULTS}

The percentage of males to females in the bycaught group was $60 \%$ male and $40 \%$ female, compared to the stranded group, which was $75 \%$ male and $25 \%$ female. The proportion of pinnipeds (30/99 or $31 \%$ ) and cetaceans (69/99 or $70 \%$ ) was very similar among bycaught and stranded animals. Calves were present in higher numbers in the bycaught group, while adults were present in higher numbers in the stranded group (Table 3).

Table 3. Gender, taxon and age characteristics of animals reviewed

\begin{tabular}{|lrrrr|} 
& \multicolumn{2}{c}{$\begin{array}{c}\text { Bycaught } \\
\text { n }\end{array}$} & \multicolumn{2}{c|}{$\begin{array}{c}\text { Stranded } \\
\text { n }\end{array}$} \\
& n & & & \\
\hline Gender & & & & \\
Male & 12 & 60 & 12 & 75 \\
Female & 8 & 40 & 4 & 25 \\
Taxon & & & & \\
Pinniped & 6 & 30 & 5 & 31 \\
Cetacean & 14 & 70 & 11 & 69 \\
Age & & & & \\
Adult & 3 & 15 & 6 & 38 \\
Subadult & 4 & 20 & 2 & 13 \\
Juvenile & 6 & 30 & 4 & 25 \\
Calf/pup/neonate & 7 & 35 & 4 & 25 \\
\hline
\end{tabular}



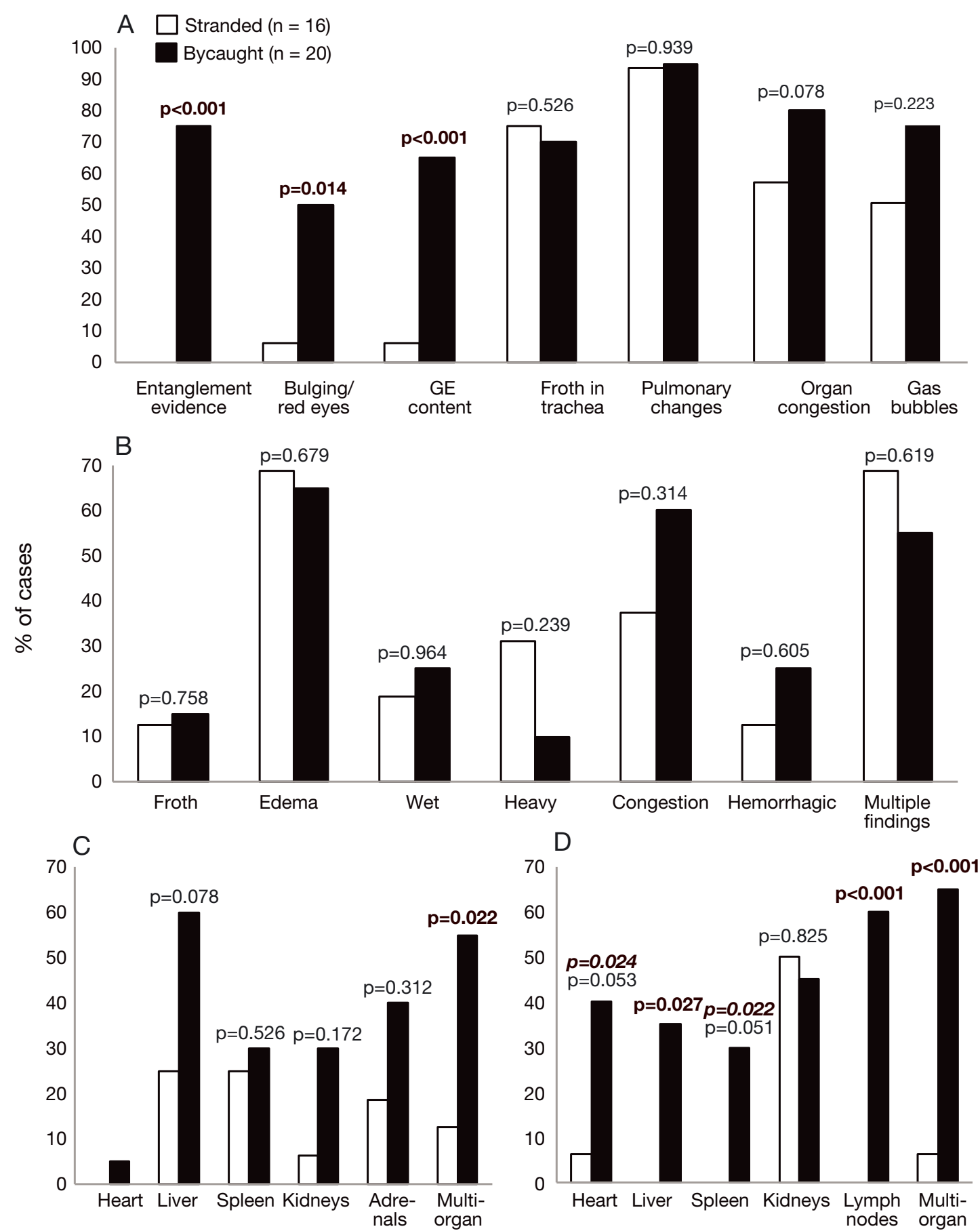

Fig. 1. (A) Comparison of peracute underwater entrapment (PUE) prevalence in 20 bycaught and 16 stranded cases. GE: gastro-esophageal. (B) Comparison of PUE prevalence of pulmonary associated changes. Multiple findings: presence of 2 or more lung changes in the same animal. (C) Comparison of congestion prevalence by location. (D) Comparison of gas bubble prevalence by location. Multi-organ: presence of congestion or gas bubbles in 2 or more organs. Significant p-values in bold: p-values (non-italics) correspond to chi-squared test results; p-values (italics) from Fisher's exact test are only reported when discrepancies between the 2 tests were found

Among the 7 key signs explored, 3 were present in significantly higher numbers in bycaught animals compared to stranded animals: external signs of acute entanglement $(p<0.001)$, red or bulging eyes $(\mathrm{p}=0.014)$, and recently ingested gastric contents $(p=0.002$; Fig. 1A). No cases $(0 / 16)$ in the stranded group reported external signs of acute entanglement, while $75 \%(15 / 20)$ of the bycaught group had evi- 
dence of acute external entanglement. Overall, significantly more, i.e. $50 \%(10 / 20)$, of the bycaught animals had red or bulging eyes than the $6 \%(1 / 16)$ of stranded animals with this finding. Recently ingested gastric contents were reported in $13 / 20(65 \%)$ of bycaught cases compared to $1 / 16$ (6\%) stranded animals with prey (Fig. 1A).

The most common gastric findings in the stranded group were empty alimentary tract, otoliths, fish vertebrae, squid beaks, parasites, or scant fluid. In only 1 stranding case were recently ingested gastric contents found, including 7 partially digested or undigested whole prey in their stomach (i.e. fish or squids).

Froth in the respiratory tree or overall presence of findings in the lung consistent with PUE (i.e. froth, edema, wet, heavy, congestion, or hemorrhagic) were not significantly different $(\mathrm{p}=0.526$ and $\mathrm{p}=$ 0.939; Fig. 1A). Froth in mouth, trachea, or bronchial tree was more frequent in stranded cases $(75 \%$; 12/16) than in bycaught cases $(70 \% ; 14 / 20$; Fig. 1A). None of the studied pulmonary changes were present in significantly different proportions. The stranded group presented a larger proportion of animals with 2 or more pulmonary changes $(69 \% ; 11 / 16)$ compared to the bycaught group $(55 \% ; 11 / 20$; Fig. 1B).

Overall presence or absence of congestion, detected by gross necropsy and histologic exam, between the groups was not significantly different $(p=0.078$; Fig. 1A), neither was the prevalence of congestion by location in the heart, liver, spleen, kidneys, or adrenal gland. However, bycaught animals were significantly more likely to have visceral organ congestion in 2 or more locations than stranded animals ( $p=0.022$; Fig. 1C). This difference increased if only histological reports were considered $(p=0.006)$. The most common location for congestion in bycaught animals was the liver $(60 \%$; $12 / 20)$, followed by adrenal gland $(40 \% ; 8 / 20)$ and spleen and kidneys $(30 \% ; 6 / 20)$. The most frequent locations reported to be congested in the stranded group were liver and spleen $(25 \% ; 4 / 16)$ followed by adrenals $(19 \% ; 6 / 21$; Fig. 1C). If only histologic reports were considered, congestion in the adrenals was significantly different between groups $(\mathrm{p}=$ 0.0150).

Overall presence or absence of gas bubbles, detected by gross necropsy and histologic exam, was not significantly different between the 2 groups ( $\mathrm{p}=$ 0.223 ; Fig. 1A). In contrast, prevalence of gas bubbles in lymph nodes and liver was significantly higher in bycaught animals compared to stranded animals ( $\mathrm{p}<$ 0.001 and $p=0.027$, respectively). Gas bubbles were also present in higher proportions in spleen and heart of bycaught animals. This difference was marginally significant when using the Chi-squared test $(p=0.051$ and $p=0.053$, respectively) and significant when using Fisher's exact test $(\mathrm{p}=0.022$ and $\mathrm{p}=$ 0.024 , respectively). Bycaught animals were also significantly more likely to have disseminated gas bubbles $(p<0.001)$, defined as detection in 2 or more locations (Fig. 1D).

The most common locations for gas bubbles in bycaught animals within the studied locations were the lymph nodes $(60 \% ; 12 / 20)$, followed by kidneys $(45 \% ; 9 / 20)$, heart $(40 \% ; 8 / 20)$, liver $(35 \% ; 7 / 20)$, and spleen $(30 \% ; 6 / 20)$. The most frequent location for gas bubbles in the stranded group was the kidneys $(50 \% ; 8 / 16)$, and 1 case was reported with gas bubbles in the heart. Gas bubbles in the stranded group were absent in liver, spleen, or lymph nodes (Fig. 1D). All these results were in agreement with results for analysis of gas bubbles reported in the histologic reports alone.

External signs of acute entanglement (Fig. 2A,B), red or bulging eyes (Fig. 2A), recently ingested gastric contents, disseminated congestion, and disseminated gas bubbles (Fig. 2C,D) were found to manifest differently and at a significantly higher rate in bycaught versus euthanized stranded marine mammals (Fig. 1).

Of the 5 significant lesions identified to be potentially PUE specific, only entanglement evidence was unique to the bycaught group: it was present in 15 out of 20 bycaught marine mammals but absent in the stranding group. Red or bulging eyes, recently ingested gastric content, disseminated congestion, and disseminated gas bubbles were found in at least 1 animal of the stranding group (Fig. 3). In the stranding group, only 5 animals presented 1 of the PUE significant findings according to this study: bulging red eyes $(n=1)$, gastric content $(n=1)$, multi-organ congestion $(n=2)$, or multi-organ gas bubbles $(n=1)$. The remaining 11 stranded animals showed an absence of PUE significant findings. In contrast, all animals in the bycaught group presented a minimum of 1 significant finding: 2 animals presented 1 PUE significant finding, 4 animals presented 2 significant PUE findings, 6 animals presented 3 significant PUE findings, 6 animals presented 4 significant PUE findings, and 2 animals presented all 5 significant PUE findings. Thus, the mode for the stranding group was 0 while the mode for the bycaught group was 4 (Fig. 3).

As a final step, we undertook to determine if the presence or absence of the lesions significant to the bycaught group might also be taxon-specific. While 

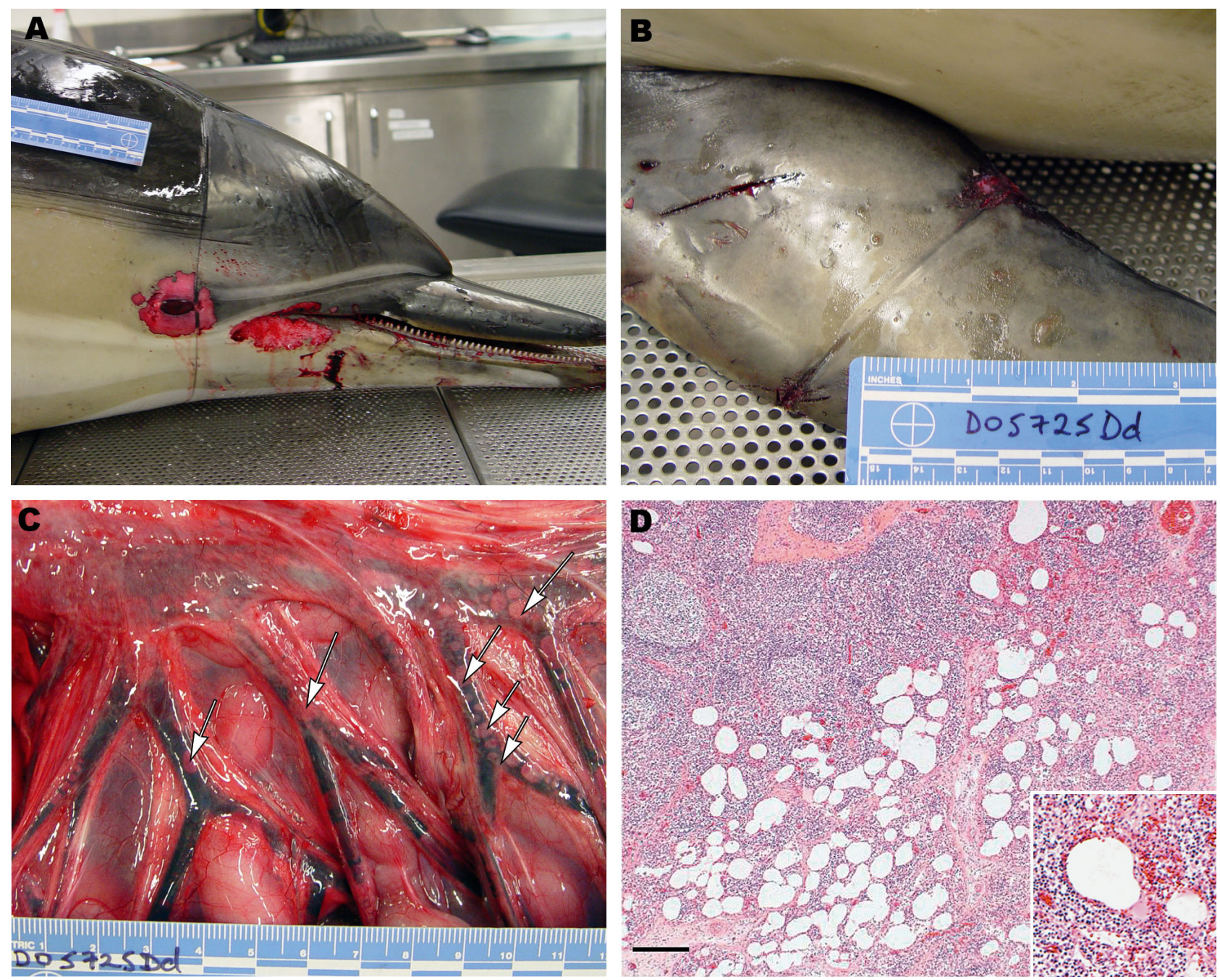

Fig. 2. Photographs of findings described for peracute underwater entrapment (PUE) in bycaught marine mammals from our study. (A) Delphinus delphis; red eyes, net/line marks around the head. (B) D. delphis; net/line marks on pectoral flipper. (C) D. delphis; presence of gas bubbles (arrows) in the mesenteric veins. (D) Phocaena phocaena; gas-filled vascular dilations in lymph node. Hematoxylin and eosin staining; scale bar $=200 \mu \mathrm{m}$

MRPP suggested that the difference between the presence of gastric contents, entanglement lesions, bulging/reddened eyes, and disseminated bubbles and gas was significantly different $(\mathrm{p}=0.001)$ between the bycaught $(\mathrm{n}=20)$ and stranded groups ( $\mathrm{n}=16$ ), there was no significant difference between the presence of the potential PUE lesions $(p=0.758)$ if the animal was a cetacean $(\mathrm{n}=25)$ or pinniped $(\mathrm{n}=$ 11). Clustering of the 2 groups (bycaught or stranded and pinniped or cetacean) using PCoA, supported this finding, demonstrating a delineation between the stranded and bycaught group (Fig. 4A) in terms of the 5 PUE-associated lesions, but no clear clustering of the presence of these lesions when the cases were compared by taxa (Fig. 4B).

\section{DISCUSSION}

Our results revealed that external signs of acute entanglement, i.e. red or bulging eyes, recently ingested gastric contents, disseminated congestion, and disseminated gas bubbles, were detected at significantly higher rates in bycaught than stranded marine mammals (Fig. 1). There was no significant difference between bycaught and stranded cases for reports of froth in the respiratory tree or PUE lung lesions.

The stranded euthanized group did not show any external lesions which were consistent with acute entanglement, such as line marks, net marks, etc. (Fig. 2A,B), while they were present in $75 \%$ of the 


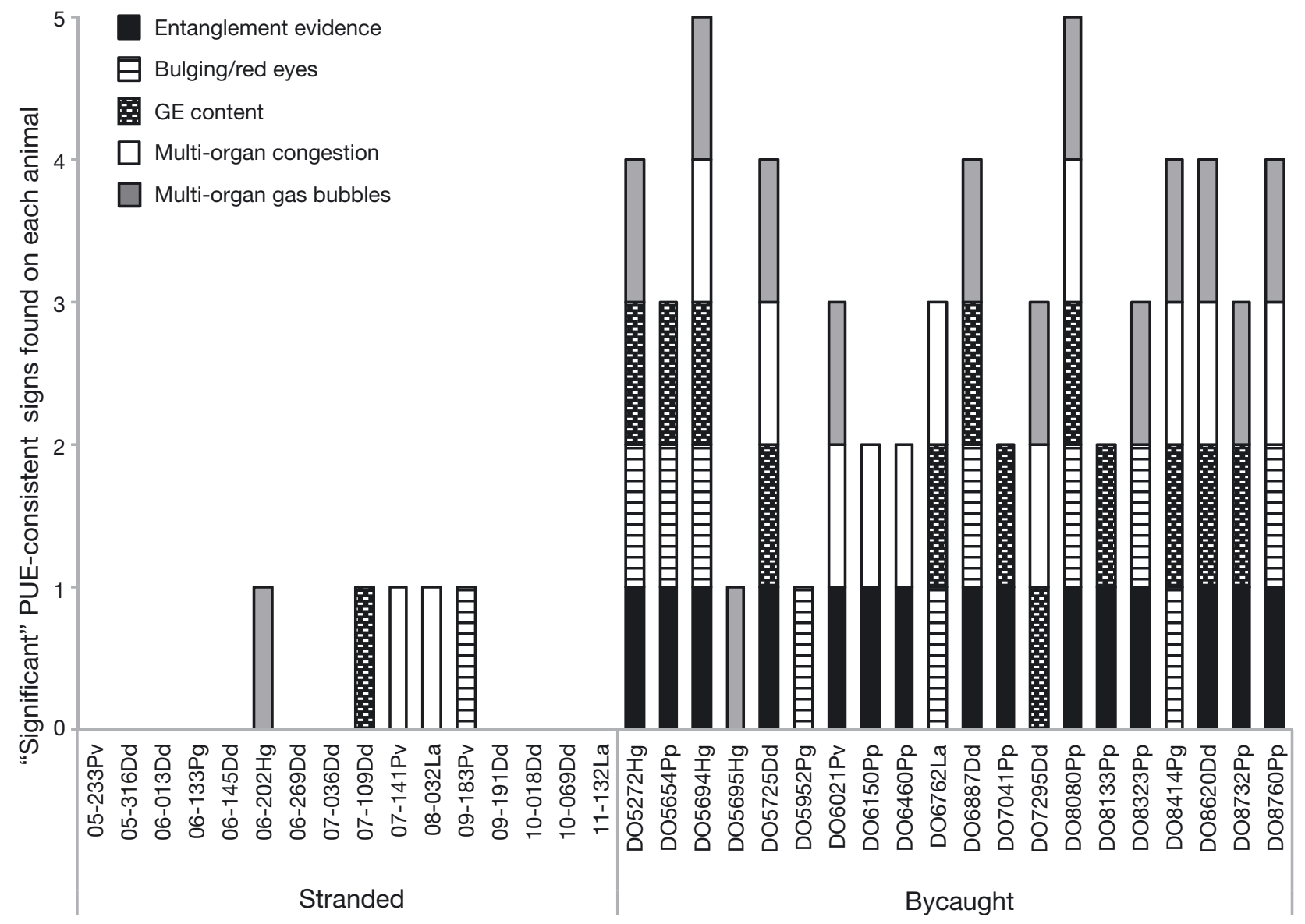

Fig. 3. Comparison of prevalence of multiple peracute underwater entrapment (PUE) signs in bycaught and stranded marine mammals. Animal ID numbers correspond to those given in Tables 1 \& 2. GE: gastroesophageal
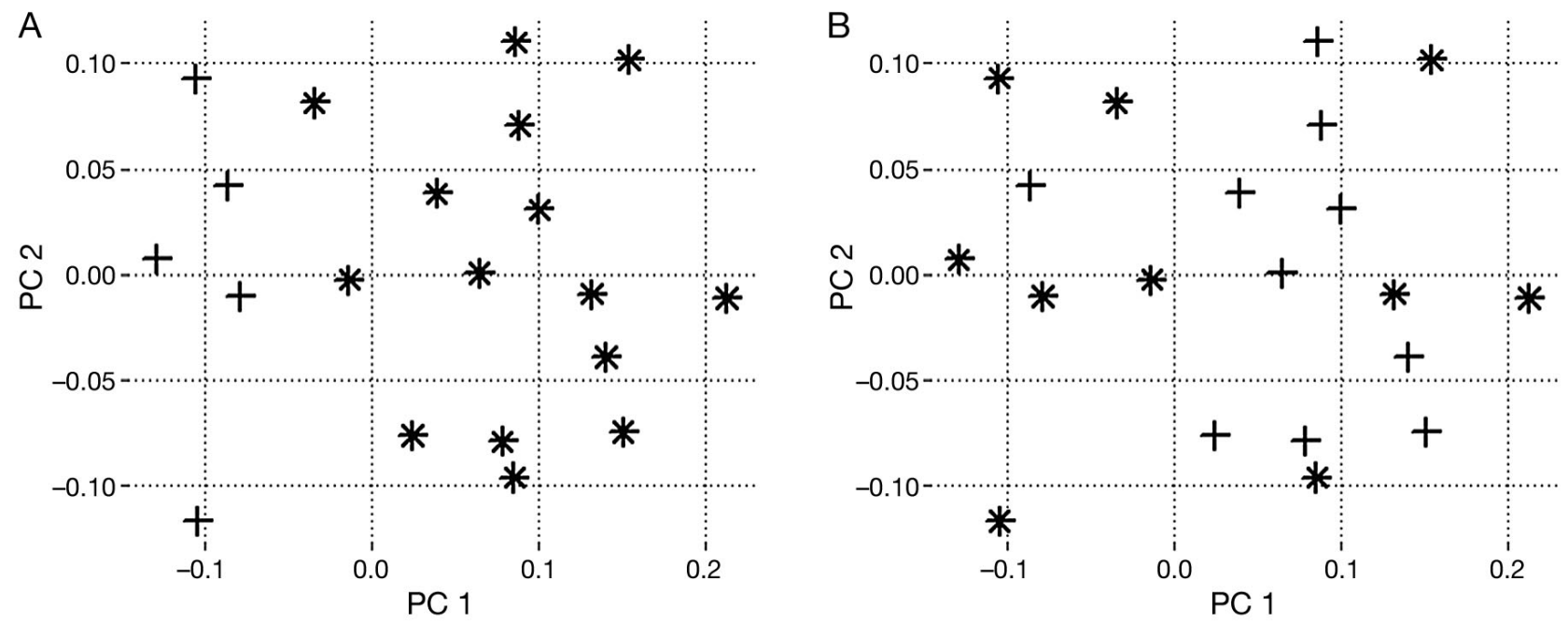

Fig. 4. Binomial distance matrix based on the presence or absence of gastric contents, entanglement evidence, red/bulging eyes, disseminated gas bubbles, and disseminated congestion for all 36 cases. (A) Group-specific clusters are evident when the cases are differentiated based on whether they were bycaught (*) or stranded (+). (B) Differentiation between cetaceans (+) or pinnipeds (*) is not observed when the presence of potential peracute underwater entrapment (PUE)-specific lesions is considered for taxa groups 
bycaught cases. Thus, evidence of acute entanglement was the most specific lesion for PUE in this study.

Of stranded euthanized cases, 1/16 presented with red or bulging eyes (Figs. 1 \& 2A). This case (IFAW09$183 \mathrm{Pv}$ ) was a canid attack case, and the animal was subsequently euthanized due to injuries. The ruptured eye was most likely caused by the attack. Grey seal attacks have been observed and reported in other locations (Leopold et al. 2015, Brownlow et al. 2016), although grey seal attacks have not been reported on Cape Cod. If this animal is removed from the calculations, there were no animals reported in the stranding group with eye changes consistent with $\mathrm{PUE}_{\text {; }}$ thus red or bulging eyes are also considered a strong indicator of PUE. However, red eyes are an unspecific lesion. Subconjunctival hemorrhages have been described in animals stranded in temporal and spatial association with acoustic disturbances (Fernández et al. 2005).

In both the bycaught and stranded groups there is also the potential that not all animals were feeding prior to entanglement or stranding. Further, bycaught animals may have voided their stomachs during the period of underwater entrapment (Lougheed et al. 1939). Indicators of recent feeding including the presence of chyle in lymphatic ducts should be scored in both stranded and bycaught gross necropsy reports as a more reliable predictor of recent feeding. The high proportion of stranded animals without gut contents is reasonable given that 10 of the stranded cases were euthanized for poor health condition and emaciation. However, the presence of whole undigested or partially digested prey in the esophagus or stomach of a stranded animal is a rare finding (Arbelo et al. 2013). In this study, only 1 stranded animal presented food remains indicative of recent ingesta $(6 \%)$. In contrast, recently ingested gastric content was found in $65 \%(13 / 20)$ of the bycaught cases, and undigested or partially digested prey were found in $35 \%(7 / 20)$ of these animals. The presence of whole undigested or partially digested prey in the stomach has also been reported in ship collisions, or acute decompression-like sickness (Arbelo et al. 2013). Although this finding is not specific to bycatch (PUE), it is a good indicator for acute death and feeding activity prior to death.

Congestion is a non-specific finding which can manifest through various physiologic processes (Herráez et al. 2013, Mosier 2017) or as a post mortem or euthanasia artifact (Grieves et al. 2008, Jepson et al. 2013). Despite the use of barbiturate euthanasia for all cases of stranded animals, stranded animals pre- sented congestion in fewer organs than bycaught animals, which were significantly more likely to present congestion in 2 or more organs. Although the organs that were studied for statistical analyses were the lungs, heart, liver, spleen, kidneys, and adrenals, congestion in other organs such as the brain was also observed. Unfortunately, these findings were not consistently described in the necropsy reports, thus statistical analyses were performed only for those organs where data were complete. Congestion is a non-specific finding, but disseminated congestion has been described together with disseminated gas bubbles as in decompression sickness (Francis \& Simon 2003). The formation of gas bubbles in a closed system such as the circulatory system necessarily increases the internal pressure. The presence of massive gas bubbles in the heart and lungs decreases the flow of blood through the lungs and cardiac output (Francis \& Simon 2003, Mosier 2017). The decreased blood flow together with the increase in internal pressure can lead to hemorrhages caused by diapedesis (Mosier 2017).

In this study, the prevalence of gas bubbles (overall presence, detected grossly during the necropsy and microscopically, vs. absence) was not significantly different between bycaught and stranded marine mammals. However, gas bubbles in 2 or more organs were found in significantly higher numbers in bycaught marine mammals compared to stranded marine mammals. Among the locations studied, gas bubbles were found more frequently in lymph nodes and livers of bycaught animals. Gas bubbles were also found more frequently (although not significantly so) in spleen or heart. Therefore, gas bubbles were systemically distributed in most bycaught animals. As noted, other organs, such as the brain, contained gas bubbles but were not consistently documented in stranding and bycatch cases. Organs to further examine presence or absence of bubbles should include brain, eyes, and muscle, in addition to vascular locations such as subcutaneous, mesenteric, coronary veins, and lumbocaudal venous plexus. Similar findings were reported in a recent prospective study where in addition to prevalence or absence of gas bubbles, the number of gas bubbles was estimated using a gas score (Bernaldo de Quirós et al. 2013b). That study concluded that the amount of gas and distribution is more important than the mere presence or absence of gas bubbles, since $78 \%$ of stranded marine mammals presented gas bubbles but none of them in large gas scores (Bernaldo de Quirós et al. 2013b). In contrast, $100 \%$ of bycaught marine mammals 
presented gas bubbles and at larger gas scores than stranded animals. Statistically significant differences were found for gas scores in fresh animals.

The prevalence of gas bubbles in stranded marine mammals noted by Bernaldo de Quirós et al. (2013b) was higher than the prevalence reported previously by Moore et al. (2009). It was suggested that the increased prevalence in stranded animals reported by Bernaldo de Quirós et al. (2013b) probably reflected greater awareness and training of stranding personnel involved in bubble examination. The prevalence reported in bycaught animals (100\%) and stranded animals (78\%) was also higher than the prevalence reported in the present study (75 and $50 \%$, respectively). These differences emphasize the need to follow a standardized protocol to search for, report, and sample gas bubbles (Bernaldo de Quirós et al. 2012a).

In our study, $50 \%$ of stranded marine mammals presented gas bubbles, all of which presented in the kidneys. Only 1 stranded animal presented gas bubbles in an additional location. Thus, stranded animals only presented gas bubbles in the kidneys except for 1 animal that presented gas bubbles in the heart in addition to the kidneys. Interestingly, Bernaldo de Quirós et al. (2013b) reported a high prevalence of perirenal subcapsular gas in 32/40 (78\%) marine mammals that were examined (including both stranded and bycaught marine mammals). The pathological interpretation of this finding remains unknown, and future research should be done in order to understand how and why gas bubbles are found in the perirenal tissue.

Gas bubbles have become a topic of interest within marine mammal pathophysiology given the potential for decompression sickness-like findings. The presence of gas bubbles in marine mammals stemming from a number of mechanisms has been reported in both live and dead stranded or bycaught animals (Fernández et al. 2005, Jepson et al. 2005, Moore et al. 2009, Bernaldo de Quirós et al. 2011, 2012b, 2013b, Dennison et al. 2012, Danil et al. 2014). Previous studies of marine mammals as well as controlled experimental models have proven that fresh animals (code 2, freshly dead; Geraci \& Lounsbury 2005) were free of relevant gas formation by putrefaction (Bernaldo de Quirós et al. 2012b, 2013a,b). Bernaldo de Quirós et al. (2013b) demonstrated that gas bubbles in fresh bycaught marine mammals were composed of nitrogen, suggesting they originated from nitrogen-saturated tissues. In this study, we included only fresh animals to avoid the interference of putrefaction in the results of the gas bubbles. This criterion is only useful for code 2 animals.

Considering previous studies on bycaught animals and the results from this study, we can conclude that gas bubbles are more widely distributed and more numerous in bycaught animals compared to stranded marine mammals, suggesting that the distribution and number of gas bubbles is a potentially important discriminating PUE criterion in fresh animals. However, gas embolism has also been described in marine mammals due to other causes such as decompression-like sickness linked to anthropogenic sound (Fernández et al. 2005) or infection by Clostridium perfringens (Danil et al. 2014); therefore, differential causes of gas embolism should always be considered and ruled out.

In both human and wildlife forensic pathology, froth in the respiratory tract has been reported as a potential indicator of drowning (Piette \& De Letter 2006). Multiple mechanisms have been proposed for the formation of froth, including breath-holding, introduction of fluid into the respiratory tract, and the interaction between pressure, edema, and residual air (Lunetta \& Modell 2005, Jepson et al. 2013). Detection of froth can also be difficult due to its disappearance during the decomposition process. Human forensic literature reports the detection of froth in only $17.3 \%$ of suspected drowning cases (Lunetta \& Modell 2005).

Our data suggest that the use of froth is a poor indicator of PUE. There was no significant difference in the proportion of bycaught animals and euthanized stranded animals with froth $(p=0.526)$. The presence of froth has potential utility, but given the challenges with identifying an etiology and the lack of significance in presence or absence between the 2 groups, we concluded that froth was not a significant differentiating criterion for PUE animals.

Human and marine mammal forensic research has focused many investigations on the manifestation of pulmonary lesions in victims of forced submersion. The most common reported findings in marine mammals are of wet, heavy, dark red lungs with edema, congestion, hemorrhage, or froth (Jepson et al. 2013). In this case review, we found no significant differences between the bycaught and stranded group in terms of these reported pulmonary lesions. However, laboratory-based research has found that barbiturate euthanasia can cause severe congestion, hemorrhage, and edema most prominently in the lungs, liver, kidneys, heart, and spleen (Prien et al. 1988) in rats, mice, rabbits, guinea pigs, sheep, non-human primates, dogs, and cats (Grieves et al. 2008). 
There is the potential that barbiturate euthanasia could have caused artefactual pulmonary changes in the stranded group and interfered with our ability to make comparisons between the lesions present in the lungs of the bycaught and stranded group. An additional potential confounding factor could be preexisting disease such as verminous pneumonia caused by heavy parasite burdens. Because of these contributing factors and the lack of significance between the groups in any of the 6 pulmonary lesions, we concluded that the pulmonary findings may not be reliable criteria of PUE in bycaught marine mammals.

The cases in this review span the period 2005-2011 and represent the work of multiple prosectors and pathologists, which challenges the study design. Protocols evolved during this period, thus the statistical analyses were limited by the anatomical locations with comparable data. Due to incomplete reports, some animals had to be removed from the study. Blank sections in pathological reports should not be interpreted as lack of findings. As a result, the number of animals included in each group was smaller than initially planned, and sample size is critical to run more powerful statistical analyses. This study emphasizes the importance of standardized complete necropsy protocols and the importance of histologic findings to strengthen the significance of the results obtained from post mortem examinations. Methods for doing this could include interactive data forms that prompt the user for routine responses, and specific fields to record gas score as defined by Bernaldo de Quirós et al. (2013b).

To undertake comparisons for the presence of potential PUE lesions between bycaught and stranded animals, both cetacean and pinniped cases were included in this study. Within-group comparisons for the bycaught and stranded group were underpowered due to small sample size. Multivariate methods were used to overcome this limitation and potentially identify if the lesions that were found to be significantly present in bycaught animals were taxa specific. While a difference was shown for the presence of the 5 PUE-associated lesions when the cases were grouped on the criteria of being stranded or bycaught, no difference was found when the cases were grouped based on taxon (cetacean vs. pinniped; Fig. 4). Therefore, taxon appears to have no effect on the presence of the lesions identified in this study to be significant to bycaught animals. Future studies using larger samples sizes that are able to undertake taxon-specific and inter-fishery comparisons will be informative to determine if there are PUE-associated lesions specific to bycaught cetaceans or pinnipeds.
Global marine mammal bycatch rates are estimated to exceed 650000 animals annually (Read et al. 2006), a large proportion of which are discarded. Retrieval of discarded bycatch as beach cast cases may occur at a lower rate in regions where prevailing tides and winds may force animals away from shore-such as Cape Cod. However, some regions are confronted with large numbers of stranded animals with non-specific post mortem findings. Currently, there is no established pathognomonic finding associated with drowning which can exclude other causes of death (Lunetta \& Modell 2005, Piette \& De Letter 2006). This can confound our ability to quantify and identify marine mammal bycatch and complicates identification of gear or practices that may make a fishery more prone to bycatch: fisheries are very complex in terms of gear and techniques, and are constantly changing.

This study provides insight to weigh the different published parameters associated with bycatch. It is notable that there is a recent tendency by some to assume that marine debris, including abandoned fishing gear, is the primary source of marine mammal entanglement (Stelfox et al. 2016), often with misleading, misrepresented evidence (Asmutis-Silvia et al. 2017). However, given that all of the bycaught cases in this study were observed takes from actively fished gear, it is important to understand that the current study should not be used to diagnose ghost gear bycatch lesions.

There is a need to better determine PUE cases within stranded animal cases (discarded bycatch), but this is logistically complicated due to the carcass condition at the time of report, since stranded animals often present with signs of decomposition. These cases still present a challenge in confidently determining if they are PUE cases.

The use of these criteria could strengthen current methods. However, this study has also shown the importance of doing prospective systematic standardized necropsies in both stranded and bycaught marine mammals, and the importance of recovery of fresh stranded and bycaught animals. Future studies with larger sample sizes for pinnipeds and cetaceans, as well as different fishing gear, may contribute to a better understanding of speciesand gear-specific markers, in addition to searching for new PUE findings or markers (Roe et al. 2013). In turn, this knowledge could be used to recommend changes in gear or techniques to mitigate bycatch.

In summary, through case reviews we identified 5 criteria from our PUE categories which present at sig- 
nificantly higher rates in bycaught than stranded marine mammals. These 5 criteria include external signs of acute entanglement, red or bulging eyes, recently ingested gastric contents, multi-organ congestion, and multi-organ gas bubbles in fresh animals. These findings largely concur with those for confirmed PUE cases in Jepson et al. (2013). Our goal was not to investigate the complex pathophysiologic processes which contribute to ultimate cause of death in marine mammals during PUE, but rather to demonstrate the utility of currently published parameters to aid in the detection at necropsy of discarded marine bycatch.

Furthermore, there is an ongoing need for better diagnosis of gas embolic conditions associated with marine mammal stranding following acoustic trauma. Differentiation of cases associated with PUE versus acoustic trauma remains a diagnostic challenge, but our study, along with a detailed history where available, should enhance the ability to make the differentiation in terms of presence or absence of findings associated with underwater entrapment.

Acknowledgements. This work was supported by the National Oceanic and Atmospheric Administration (NOAA) John H. Prescott Program NA12NMF4390144. The WHOI Marine Mammal Center, Wick and Sloan Simmons, and the University of Las Palmas de Gran Canaria provided postdoctoral funding for Y.B.Q. We thank the NOAA Northeast Fisheries Observer Program staff and observers, captains and crews of the fishing vessels that helped with the recovery of bycaught animals, and the staff and volunteers with the International Fund for Animal Welfare.

\section{LITERATURE CITED}

Arbelo M, Espinosa de los Monteros A, Herráez P, Andrada $M$ and others (2013) Pathology and causes of death of stranded cetaceans in the Canary Islands (1999-2005). Dis Aquat Org 103:87-99

Asmutis-Silvia R, Barco S, Cole T, Henry A and others (2017) Rebuttal to published article 'A review of ghost gear entanglement amongst marine mammals, reptiles and elasmobranchs' by M. Stelfox, J. Hudgins, and M. Sweet. Mar Pollut Bull 117:554-555

Bernaldo de Quirós Y, González-Díaz Ó, Saavedra P, Arbelo $M$ and others (2011) Methodology for in situ gas sampling, transport and laboratory analysis of gases from stranded cetaceans. Sci Rep 1:193

* Bernaldo de Quirós Y, González-Díaz Ó, Arbelo M, Andrada M, Fernandez A (2012a) Protocol for gas sampling and analysis in stranded marine mammals. Protoc Exch 2012: doi:10.1038/protex.2012.002

Bernaldo de Quirós Y, González-Diaz O, Arbelo M, Sierra E, Sacchini S, Fernández A (2012b) Decompression vs. decomposition: distribution, amount, and gas composition of bubbles in stranded marine mammals. Front Physiol 3: 177
Bernaldo de Quirós Y, González-Díaz O, Møllerløkken A, Brubakk AO, Hjelde A, Saavedra P, Fernández A (2013a) Differentiation at autopsy between in vivo gas embolism and putrefaction using gas composition analysis. Int $\mathrm{J}$ Legal Med 127:437-445

* Bernaldo de Quirós Y, Seewald JS, Sylva SP, Greer B, Niemeyer M, Bogomolni AL, Moore MJ (2013b) Compositional discrimination of decompression and decomposition gas bubbles in bycaught seals and dolphins. PLOS ONE 8:e83994

Berta A, Sumich JL, Kovacs KM, Folkens PA, Adam PJ (2006) Respiration and diving physiology. In: Marine mammals, 2nd edn. Academic Press, Burlington, MA, p 237-269

Bjorge A, Tolley KA (2017) Harbor porpoise Phocoena phocoena. In: Würsig B, Thewissen JGM, Kovacs K (eds) Encyclopedia of marine mammals, 3rd edn. Academic Press, San Diego, CA, p 448-451

Brownlow A, Onoufriou J, Bishop A, Davison N, Thompson D (2016) Corkscrew seals: grey seal (Halichoerus grypus) infanticide and cannibalism may indicate the cause of spiral lacerations in seals. PLOS ONE 11:e0156464

Cox TM, Read AJ, Barco S, Evans J and others (1998) Documenting the bycatch of harbor porpoises, Phocoena phocoena, in coastal gillnet fisheries from stranded carcasses. Fish Bull 96:727-734

พDanil K, St. Leger JA, Dennison S, Bernaldo de Quirós Y, Scadeng M, Nilson E, Beaulieu N (2014) Clostridium perfringens septicemia in a long-beaked common dolphin Delphinus capensis: an etiology of gas bubble accumulation in cetaceans. Dis Aquat Org 111:183-190

* Dennison S, Moore MJ, Fahlman A, Moore K and others (2012) Bubbles in live-stranded dolphins. Proc R Soc B 279:1396-1404

Di Maio DJ, Di Maio VJM (1993) Forensic pathology. CRC Press, Boca Raton, FL

Duignan PJ, Gibbs NJ, Jones GW (2003) Autopsy of cetaceans incidentally caught in fishing operations 1997/98, 1999/ 2000, and 2000/01. DOC Science Internal Series 119. Department of Conservation, Wellington

*Fernández A, Edwards JF, Rodriguez F, Espinosa de los Monteros A and others (2005) 'Gas and fat embolic syndrome' involving a mass stranding of beaked whales (Family Ziphiidae) exposed to anthropogenic sonar signals. Vet Pathol 42:446-457

Francis TJR, Simon JM (2003) Pathology of decompression sickness. In: Brubakk AO, Neuman TS (eds) Bennett and Elliott's physiology and medicine of diving. Saunders, New York, NY, p 530-556

García-Párraga D, Crespo-Picazo JL, Bernaldo de Quirós Y, Cervera V and others (2014) Decompression sickness ('the bends') in sea turtles. Dis Aquat Org 111:191-205

Geraci JR, Lounsbury VJ (2005) Marine mammals ashore: a field guide for strandings, 2nd edn. National Aquarium in Baltimore, Baltimore, MD

* Grieves JL, Dick EJ Jr, Schlabritz-Loutsevitch NE, Butler SD and others (2008) Barbiturate euthanasia solution-induced tissue artifact in nonhuman primates. J Med Primatol 37 : $154-161$

Hall A, Russel D (2017) Gray seal Halichoerus grypus. In: Würsig B, Thewissen JGM, Kovacs K (eds) Encyclopedia of marine mammals, 3rd edn. Academic Press, San Diego, CA, p 420-422

*Herráez P, Espinosa de los Monteros A, Fernández A, Edwards JF, Sacchini S, Sierra E (2013) Capture myopathy in live-stranded cetaceans. Vet J 196:181-188 
Jepson PD, Deaville R, Patterson IAP, Pocknell AM and others (2005) Acute and chronic gas bubble lesions in cetaceans stranded in the United Kingdom. Vet Pathol 42:291-305

Jepson PD, Barbieri M, Barco SG, Bernaldo de Quirós Y, Bogomolni AL, Danil K, Rowles T (2013) Peracute underwater entrapment of pinnipeds and cetaceans. In: Moore MJ, Van Der Hoop J, Barco SG, Costidis AM and others (eds) Criteria and case definitions for serious injury and death of pinnipeds and cetaceans caused by anthropogenic trauma. Dis Aquat Org 103:235-239

Knieriem A, García-Hartmann M (2001) Comparative histopathology of lungs from by-caught Atlantic whitesided dolphins (Leucopleurus acutus). Aquat Mamm 27:73-81

Kuiken T (1994) A review of the criteria for the diagnosis of by-catch in cetaceans. In: Kuiken T (ed) Diagnosis of bycatch in cetaceans. Proc 2nd ECS Workshop on Cetacean Pathology, Montpelier. European Cetacean Society, Saskatoon, p 38-43

Leopold MF, Begeman L, van Bleijswijk JDL, IJsseldijk LL, Witte HJ, Gröne A (2015) Exposing the grey seal as a major predator of harbour porpoises. Proc R Soc B 282: 20142429

Lougheed DW, Janes JM, Hall GE (1939) Physiological studies in experimental asphyxia and drowning. Can Med Assoc J 40:423-428

Ludders JW, Schmidt RH, Dein FJ, Klein PN (2009) Drowning is not euthanasia. Wildl Soc Bull 27:666-670

Lunetta P, Modell JH (2005) Macroscopical, microscopical, and laboratory findings in drowning victims. In: Tsokos $\mathrm{M}$ (ed) Forensic pathology reviews, Book 3. Humana Press, Totowa, NJ, p 3-77

Moore KT, Barco SG (2013) Handbook for recognizing, evaluating, and documenting human interaction in stranded cetaceans and pinnipeds. Tech Memo NOAA-TM-NMFSSWFSC-510. US Department of Commerce, NOAA, NMFS, SFSC. https://swfsc.noaa.gov/publications/TM/ SWFSC/NOAA-TM-NMFS-SWFSC-510.pdf

Moore MJ, Bogomolni AL, Dennison SE, Early G and others (2009) Gas bubbles in seals, dolphins, and porpoises entangled and drowned at depth in gillnets. Vet Pathol 46:536-547

Moore MJ, Hammar T, Arruda J, Cramer S, Dennison S, Montie E, Fahlman A (2011) Hyperbaric computed tomographic measurement of lung compression in seals and dolphins. J Exp Biol 214:2390-2397

Moore MJ, van der Hoop J, Barco SG, Costidis AM and others (eds) (2013) Criteria and case definitions for serious

Editorial responsibility: Stephen Raverty, Abbotsford, British Columbia, Canada injury and death of pinnipeds and cetaceans caused by anthropogenic trauma. Dis Aquat Org 103:229-264

Mosier DA (2017) Vascular disorders and thrombosis. In: Zachary JF (ed) Pathologic basis of veterinary disease. Elsevier, St. Louis, MO

Oksanen J, Blanchet FG, Friendly M, Kindt R and others (2017) Vegan: community ecology package. https:// cran.r-project.org/web/packages/vegan/vegan.pdf

Papadodima SA, Athanaselis SA, Skliros E, Spiliopoulou CA (2010) Forensic investigation of submersion deaths. Int J Clin Pract 64:75-83

*Piantadosi CA, Thalmann ED (2004) Pathology: whales, sonar and decompression sickness [Arising from: Jepson et al., Nature 425:575-576 (2003)]. Nature 428, doi: 10.1038/nature02527a

Piette MHA, De Letter EA (2006) Drowning: still a difficult autopsy diagnosis. Forensic Sci Int 163:1-9

* Prien T, Traber DL, Linares HA, Davenport SL (1988) Hemolysis and artifactual lung damage induced by an euthanasia agent. Lab Anim 22:170-172

Pugliares KR, Bogomolni AL, Touhey KM, Herzig SM, Harry CT, Moore MJ (2007) Marine mammal necropsy: an introductory guide for stranding responders and field biologists. WHOI Tech Rep. Woods Hole Oceanographic Institution, Woods Hole, MA. https://hdl.handle.net/ 1912/1823

R Core Team (2017) R: a language and environment for statistical computing. R Foundation for Statistical Computing, Vienna

Read AJ, Drinker P, Northridge S (2006) Bycatch of marine mammals in U.S. and global fisheries. Conserv Biol 20: 163-169

Roe WD, Spraker TR, Duncan CG, Owen M, Charles JB (2013) Postmortem stability of S100B in the aqueous humor of northern fur seals (Callorhinus ursinus). J Vet Diagn Invest 25:627-629

* Stelfox M, Hudgins J, Sweet M (2016) A review of ghost gear entanglement amongst marine mammals, reptiles and elasmobranchs. Mar Pollut Bull 111:6-17

Stewart BS (2017) Diving behavior. In: Würsig B, Thewissen JGM, Kovacs K (eds) Encyclopedia of marine mammals, 3rd edn. Academic Press, San Diego, CA, p 262-267

*Vann RD, Butler FK, Mitchell SJ, Moon RE (2011) Decompression illness. Lancet 377:153-164

*Williams TM, Kendall TL, Richter BP, Ribeiro-French CR and others (2017) Swimming and diving energetics in dolphins: a stroke-by-stroke analysis for predicting the cost of flight responses in wild odontocetes. J Exp Biol 220:1135-1145

Submitted: July 24, 2017; Accepted: November 6, 2017 Proofs received from author(s): December 20, 2017 